\title{
Design and Performance Analysis of Micro Wind Turbine for Fiji
}

\author{
Ashneel Deo, Jai Nendran Goundar, Sumesh Narayan, and Niranjwan Chettiar
}

\begin{abstract}
Today's major research area is based on finding alternatives to fossil fuels. Wind energy can contribute significantly towards renewable energy production. A functional wind turbine built locally proposes a huge impact for Fiji and the Pacific Islands renewable energy industry. The design has to take into consideration the wind speed of the pacific which is quite different from other countries. A low Reynolds number airfoil was selected and modified for horizontal axis wind turbine (HAWT) and its aerodynamic characteristic was studied. The analysis were done using XFoil software, the numerical results were validated with experimental results before analysis were done. The Q-blade Software is used to design the blade for the wind turbine. The cut in velocity of wind turbine is $3 \mathrm{~ms}^{-1}$, which is a big achievement when it comes for the power generation. The rated power is 50 watts at rated velocity of $6.5 \mathrm{~ms}^{-1}$ and the cut of velocity is at $20 \mathrm{~ms}^{-1}$. The numerical results were validated with experimental results. The peak power after measurement was 23.73 watts at wind speed of $8 \mathrm{~ms}^{-1}$.
\end{abstract}

Index Terms - Renewable energy, horizontal axis micro wind turbine, airfoils, blade design.

\section{NOMENCLATURE}

$C \quad \operatorname{chord}(\mathrm{m})$

$C_{d} \quad$ Drag Coefficient $\left(\mathrm{D} / 1 / 2 \rho \mathrm{AV}_{\mathrm{r}}{ }^{2}\right)$

$C_{l} \quad$ Lift Coefficient $\left(\mathrm{L} / 1 / 2 \rho \mathrm{AV}_{\mathrm{r}}{ }^{2}\right)$

$D \quad \operatorname{Drag}(\mathrm{N})$

$L \quad$ Lift (N)

$P \quad$ rotor Power (W)

$r \quad$ radius of local blade element (m)

$\mathrm{R}$ blade radius (m)

$t$ maximum thickness of airfoil (m)

$V_{r}$ relative velocity of rotating blade $\sqrt{U_{o}^{2}(1-a)^{2}+\Omega^{2} r^{2}\left(1+a^{\prime}\right)^{2}}$

$U_{o} \quad$ uncorrected freestream velocity $(\mathrm{m} / \mathrm{s})$

$a$ axial flow induction factor

$a^{\prime}$ tangential flow induction factor

$\Omega \quad$ rotational speed (rad/s)

$\varepsilon^{s b} \quad$ solid blockage correction factor

Manuscript received October 5, 2014; revised August 24, 2015.

A. Deo is with the Section of Mechanical Engineering, The University of the South Pacific, Laucala Campus, Suva, Fiji (e-mail: deo_a@usp.ac.fj).

J. N. Goundar and S. Narayan are with the Section of Mechanical Engineering, The University of the South Pacific, Laucala Campus, Suva, Fiji (e-mail: goundar_j@usp.ac.fj, narayan_su@usp.ac.fj).

N. Chettiar is with the Department of properties and facilities, The University of the South Pacific, Laucala Campus, Suva, Fiji (e-mail: chettiar_n@usp.ac.fj).

\author{
$K_{1}$ wind-tunnel correction constant for solid blockage \\ effects (0.74) \\ $M_{v}$ model volume $\left(\mathrm{m}^{3}\right)$
}

\section{INTRODUCTION}

Climate change issues, increased demand of electricity, increased cost of fuel transportation and dependence on fossil fuels by the South Pacific Countries are the reasons for the fundamental quest towards harnessing energy via renewable energy sources. Government policies in Fiji are strengthening and plans are put in place to increase renewable energy in energy mix by $90 \%$ by 2020 [1], [2]. Wind energy is a renewable energy source that could make a significant contribution to the Pacific Island Countries energy supply. A functional wind turbine built locally proposes a huge impact for Fiji and the Pacific Islands renewable energy industry. The potential power production from wind energy depends on wind speed and wind speeds very on a global, regional and even local basis often following seasonal patterns [3]. Hence, the design has to take into consideration the wind speed in the region which is in a range of $4-7 \mathrm{~m} / \mathrm{s}$ at a height of $10-20 \mathrm{~m}$ above ground [4]. Micro wind turbines are fast gaining reputation due to their capacity to meet community or domestic needs in remote areas with comparatively easier installation and lower cost than large wind turbines. Micro-wind turbines have potential for growth in the small Pacific Island Countries.

A micro-generation system gives an opportunity of for development of renewable energy sources, research, technological innovation, and resource efficiency in the Pacific Island Countries. A micro wind turbine should always be simple, easy to install device that a person could buy in any shop and be able to install at his home without any hassle. Not only that, electricity production mechanisms such as these helps people to be self-sufficient and use less electricity from the grid [5], [6]. The operating wind speeds for the turbines also plays a vital role in the power production of these turbines, therefore, wind speeds should match the cut in speeds for the turbines. Turbines designed for higher wind speeds do not do well in case of lower wind speeds and when dealing with low wind speeds, airfoil design is absolute critical. For the micro-wind turbine blade design, the choice of airfoils for different sections and the distribution of chords and twists are essential. The generally used NACA airfoils are not suitable for wind turbines that need to function in regions of low wind speed. The NACA airfoils are appropriate for uses where the Reynolds numbers (Re) are high and the angles of attack are comparatively small [4].

The present investigation uses a newly designed flat back 
airfoil. The advantage of flat back airfoil is that it improves the structural volume; easy for fabrication, building, and it also enhances the lift characteristics for thick airfoil. According to [7] a flat back trailing edges airfoil was more effective with a flat trailing edge. A rounded trailing edge corner causes the flow to follow the base curvature causing more acceleration than the sharp trailing edge corner flow separation. This flow acceleration causes significantly lower pressures behind the airfoil and is the cause of a larger drag penalty. The current work is aimed to get more insight of the flow characteristic and lift to drag behavior of a newly designed USPB_01 flat back airfoil at different Re and $\alpha$, to assess its application in micro-wind turbine for low wind speed of 4-7 m/s which is common in the pacific region. Finally, the paper also discusses the model testing of the turbine mounted at a height of $10 \mathrm{~m}$ above the ground.

\section{Wind ENERgy Potential Study At LAUCALA BAy, FiJi}

Before any wind turbine is design one needs to study the wind patterns and behavior at the location where the wind turbine will be installed. Therefore, a wind speed study was done, by collecting measurement data for 600 days. The measurement was done at Laucala Bay Suva Fiji, Lat: -18.15, Lon: 178.45, the wind speed for 600 days and the average for each day were calculated as shown in the Fig. 1 . Then the wind speed of each day was averaged with the number of days. The mean wind speed was $7.85 \mathrm{~m} / \mathrm{s}$. From closer observation of the graph there is a tremendous variation in the wind speed and then for the design purpose the wind speed was taken as $9.5 \mathrm{~m} / \mathrm{s}$ since the average velocity for most of the days is more than $9.5 \mathrm{~m} / \mathrm{s}$.

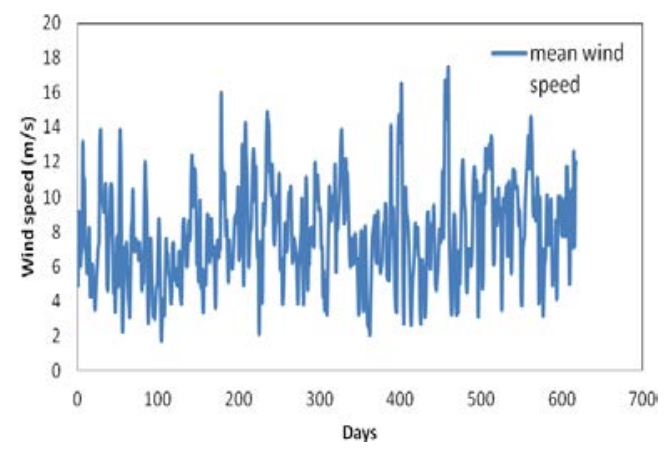

Fig. 1. Measured wind speed at laucala campus for 600 days.

\section{AIRFOIL SELECTION}

The flat back airfoil USPB_01 was selected to be modified and used as the blade profile for the micro wind turbine. The selection was done after studying the aerodynamic characteristics of several airfoils in USPX-XX airfoil series and SXXXX series airfoils and some of the airfoil performances are given in Fig. 2. These airfoils are known to have good aerodynamic characteristics [8]. Coefficient of lift to drag ratio (L/D ratio) is one of the important and useful parameters in assessing the performance of the airfoils for initial selection and modification. USPB_01 was found to one of the best performing airfoils and hence, it was further subjected to detail analysis and the results are presented here.
USPB_01 has the trail gap 0.3, maximum thickness 0.1059 and maximum camber of 0.055 , this airfoil was modified for its optimum performance and its aerodynamic characteristics were analyzed using XFoil software. The modified airfoil has a trailing gap of 0.025 , bending distances of 0.4 , maximum thickness of 0.085 and maximum chamber of 0.05 , as shown on the Fig. 3. A similar study was performed by McGowan et al. [9] and the airfoil profile and wind turbine design was optimized, however, using only numerical analysis.

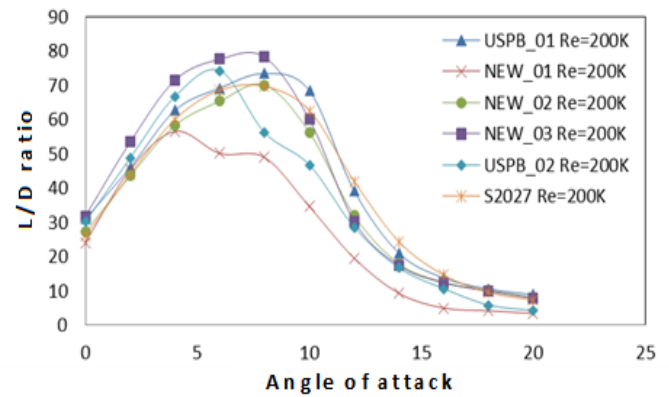

Fig. 2. Variation of L/D ratio against angle of attack for different airfoils.

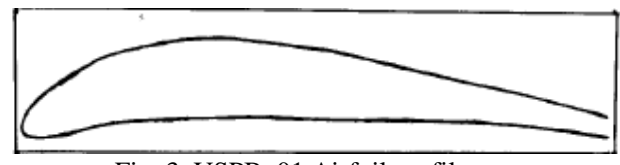

Fig. 3. USPB_01 Airfoil profile.

In the modification process, the $\mathrm{L} / \mathrm{D}$ ratio was monitored for a range of angles of attack, this was done to optimize the turbine performance.

\section{NUMERICAL AND EXPERIMENTAL VALIDATION}

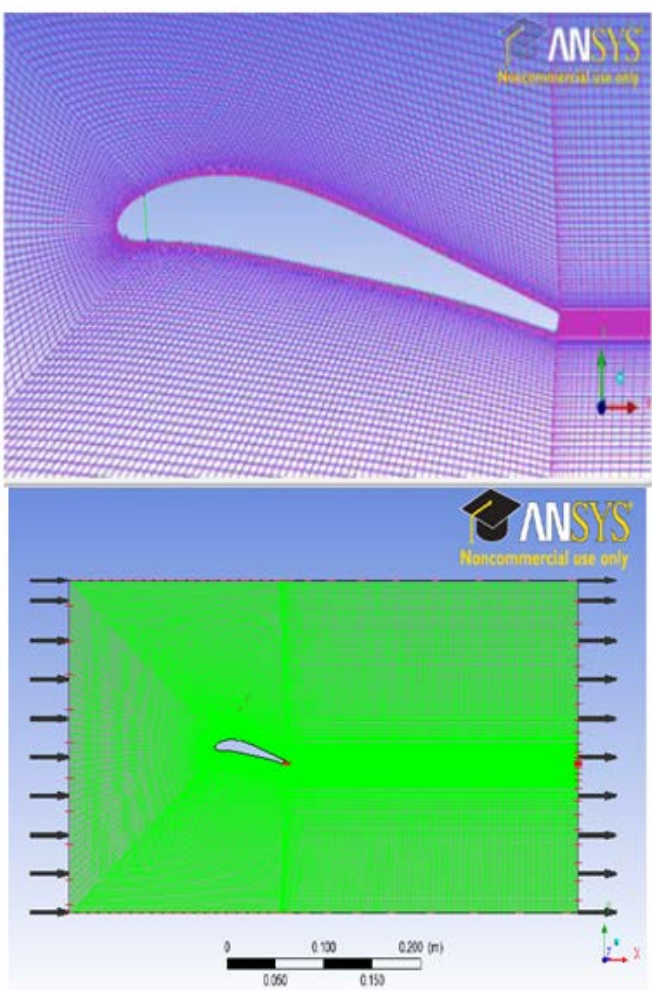

Fig. 4. Airfoil meshing.

The numerical results (Xfoil and Ansys CFX) were validated with the experimental results. The USPB_01 
profile was analyzed in the ANSYIS-CFX software, The ANSYS-CFX solves the Reynolds averaged navies stoke equation (RANSE).The discretization used in ANSYS-CFX is based on finite-volume method (FVM). For the meshing Ansys ICEM CFD was used. The domain was chosen such that the size of the airfoil is distanced 10 times the chord length from the airfoil to the edge. The meshing of the airfoil geometry was based on the O-grid and C-grid topology and it was resolved properly due to the boundary layer. From mesh size of 123240 nodes onwards the variation on the coefficient of lift was within $0.11 \%$. Therefore, choosing high node was no beneficial use as it just increases the simulation time.

Ansys CFX Pre was used to define domains and boundary conditions, the mesh was solved using Ansys CFX solver, and results were viewed in Ansys CFX post as shown in Fig. 4. For convergence control, maximum coefficient loop was set to 10, and the lift and drag coefficient was monitored.

The Experiment was conducted in the open circuit, suction type low speed wind tunnel at Reynolds number of 200,000. The flow in the wind tunnel was generated by a single stage centrifugal fan, which has the discharge rate of $4.53 \mathrm{~m}^{3} / \mathrm{s}$ at a pressure head of $996.6 \mathrm{~Pa}$, at fan speed of $2253 \mathrm{rpm}$. A free stream velocity from $3 \mathrm{~m} / \mathrm{s}$ to $50 \mathrm{~m} / \mathrm{s}$ can be achieved in the test section (303 $\mathrm{mm} \times 303 \mathrm{~mm} \times 1000 \mathrm{~m})$.

Solid blockage caused by the walls of the test section increases the flow velocity in the test section. The solid blockage was corrected using the equations 1 and 2 [10].

$$
\begin{array}{r}
V=V_{u}\left(1+\varepsilon^{s b}\right) \\
\varepsilon^{s b}=\frac{k_{1}\left(m_{v}\right)}{(c s a)^{\frac{3}{2}}}
\end{array}
$$

A model airfoil was fabricated with the span of $70 \mathrm{~mm}$ and length of $300 \mathrm{~mm}$ as shown on the Fig. 5 . Tests were carried out at Re of 200,000 based on the chord length and corrected freestream velocity. A dynamometer was used to measure the lift and drag forces on the airfoil. Xfoil analysis was carried for USPB_01 airfoil to compare and verify experimental result obtained using the wind tunnel.

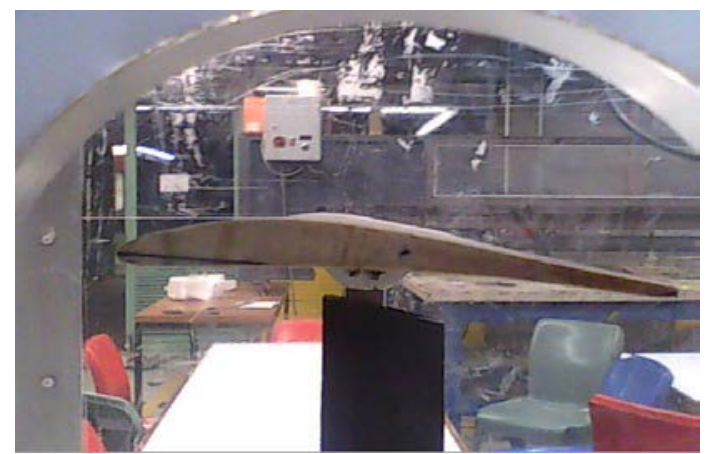

Fig. 5. A model of USPB_01 airfoil mounted on the wind tunnel

Fig. 6 shows the Coeffiecent of lift vesus coefficient of drag determined using numerical and experimental method, The drag is sligtly under predicted using numerical method, otherwise all three curves follow similar thrend.

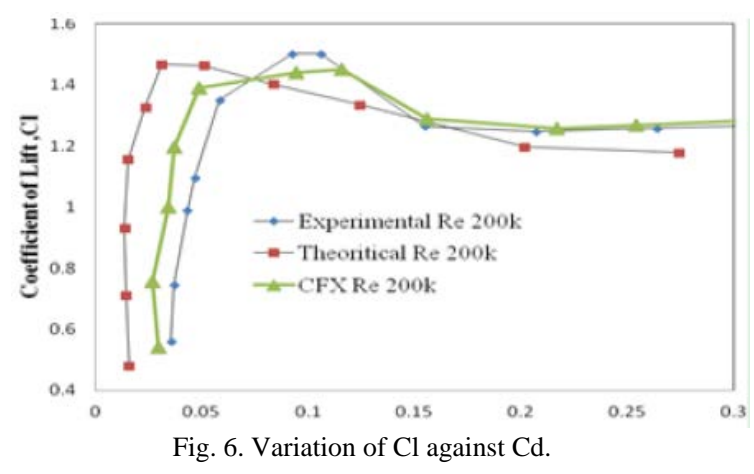

\section{TURBINE DESIGN AND MANUFACTURING}

The turbine was designed using Q-blade software, the USPB_01 profile was loaded, turbine details and operating parameters were set and the turbine performance was monitored. Q Blade also includes extensive post processing functionally for rotor and turbine simulation and gives deep insight into all relevant blades and rotor variables [8].The blade was design with Specification of rated power of 50 watts, cut in velocity of $3 \mathrm{~m} / \mathrm{s}$ cut out speed of $20 \mathrm{~m} / \mathrm{s}$, blade length of $0.5 \mathrm{~m}$, rotor diameter of $150 \mathrm{~cm}$.

For good aerodynamic performance the chord distribution must follow the hyperbolic curve, for manufacturing point of view the chord distribution is usually linear. Equation 3 gives theoretically optimum chord distribution for the turbine blade [11].

$$
\mathrm{C}_{\mathrm{opt}}=\frac{2 \pi r}{z} \frac{8}{9 C_{L}} \frac{V_{w d}}{\operatorname{TSR}\left(V_{r}\right)}
$$

However, the chord distribution is modified for optimum efficiency and blade strength. The optimized chord distribution for the blade is shown in Fig. 7.

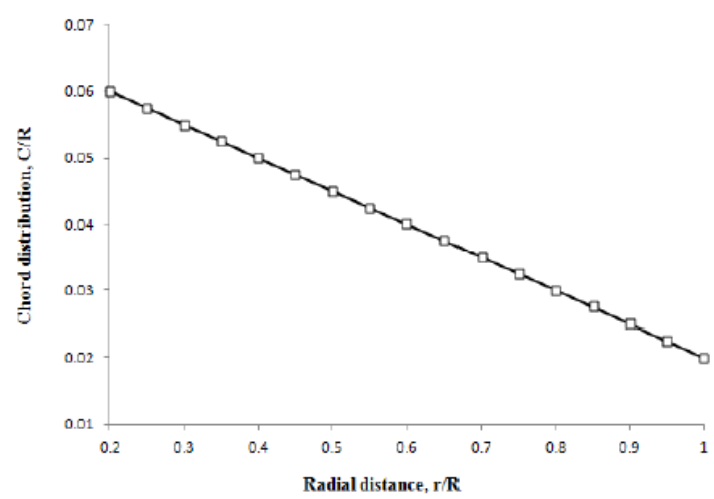

Fig. 7. Chord distribution of turbine blade.

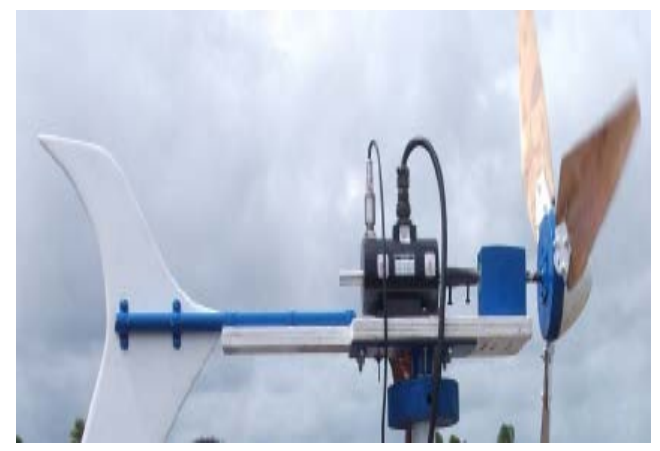

Fig. 8. The model of wind turbine. 
Manufacturing process of the whole turbine was done in the mechanical workshop at the University of the South Pacific. The fabrication was done with the machine available in the mechanical workshop. The dakua wood was used in the fabrication of the blades. Fig. 8 shows the model of the wind turbine fabricated for testing.

\section{PERFormanCE ANALYSIS}

Fig. 9 shows the power output of the turbine measured experimentally. The Torque and RPM of the rotor was measured using Torque sensor, model TRC-2K (01200010) with the capacity of $2 \mathrm{kgf}-\mathrm{m}$. The measurements were done for 3 blade pitch angles, $8^{\circ}, 18^{\circ}$ and $25^{\circ}$. The results show slight decrease in power with increase in pitch angle, for wind speeds $3 \mathrm{~m} / \mathrm{s}$ to $6 \mathrm{~m} / \mathrm{s}$, after $6 \mathrm{~m} / \mathrm{s}$ the power output curve follows similar trend for pitch angles between $8^{\circ}-25^{\circ}$. The blade pitch of this turbine can be regulated for the real case to maximize its performance. The turbine produces maximum power of $15 \mathrm{~kW}$ at wind speed of $3.5 \mathrm{~m} / \mathrm{s}$, and 24 $\mathrm{kW}$ at $8 \mathrm{~m} / \mathrm{s}$, it is the maximum speed at which measurements were taken. Further, similar results were obtained by Graeme et al [12] and they showed enhanced performance with the optimized airfoil and wind turbine.

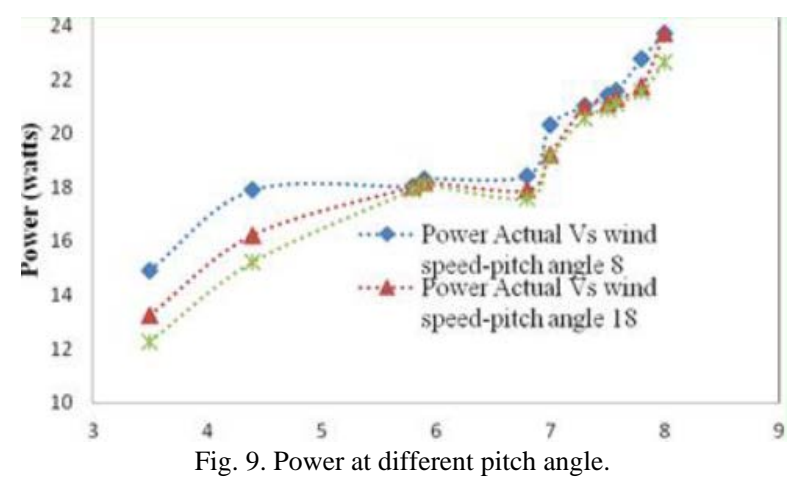

\section{CONCLUSION}

A micro wind turbine has been successfully designed for pacific island countries like Fiji, the average wind is slightly lower in these locations. The designed wind turbine can be manufactured with low cost and giving desired output achieving power up to $24 \mathrm{~kW}$ at $8 \mathrm{~m} / \mathrm{s}$. Such turbines can be utilized to generate electricity in remote areas. The future work includes, improving the turbine performance and including pitch regulating mechanism to optimize the turbine performance.

\section{REFERENCES}

[1] FEA, "Fiji electricity authority annual report," Fiji Electricity Authority (FEA), 2011.

[2] IRENA, "IRENA Policy brief: policy challenges for renewable energy deployment in pacific island countries and territories,” International Renewable Energy Agency (IRENA), 2012.

[3] G. Owens, "Best practices guide: Economic and financial evaluation of renewable energy projects," Energy and Environment Training Program, Office of Energy, Environment and Technology, Global Bureau, Center for Environment, USAID, 2002.

[4] M. R. Ahmed, S. Narayan, M. A. Zullah, and Y. H. Lee, "Experimental and numerical studies on a low Reynolds number airfoil for wind turbine blades,” Journal of Fluids Sciences and Technology, vol. 6, pp. 357-367, 2011.

[5] A. Gagliano, F. Nocera, F. Patania, and A. Capizzi, "Assessment of micro-wind turbines performance in the urban environments: An aided methodology through geographical information systems," International Journal of Energy and Environmental Engineering, vol. 4, pp. 43-52, 2013.

[6] A. S. Bahaj, L. Myers, and P. A. B. James, "Urban energy generation: Influence of micro-wind turbine output on electricity consumption in buildings,” Journal of Energy and Building, vol. 2, pp. 154-165, 2007.

[7] C. P. C. Dam, D. L. Kahn, and D. E. Berg, "Trailing edge modifications for flat back airfoils," Sandia National Laboratories, University of California, California, 2008.

[8] K. R. Ram, S. Lal, and M. R. Ahmed, "Airfoil optimization for small wind turbines using multi objective genetic algorithm," in Proc. the ASME 2012 International Mechanical Engineering Congress \& exposition, 2012, Houston, Texas, USA.

[9] R. McGowan, K. Morillas, A. Pendharkar, and M. Pinder, "Optimization of a vertical Axis MicroWind turbine for low tip speed ratio operation," The Daniel Guggenheim School of Aerospace Engineering Georgia Institute of Technology, Atlanta, GA, 30332, United States, 2011.

[10] J. B. Barlow, W. H. Rae, and J. R. Pope, Low Speed Wind Tunnel Testing, New York: Wiley Interscience, 1999, pp. 44-60.

[11] E. Hau, Wind Turbines; Fundamentals, Technologies, Application, Economics, Germany: Springer, 2006, pp. 66-80.

[12] G. I. Comyn, S. D. Nobes, and B. A. Fleck, "Performance evaluation and wake study of a micro wind turbine," Department of Mechanical Engineering, University of Alberta, Edmonton, AB, Canada, 2011.

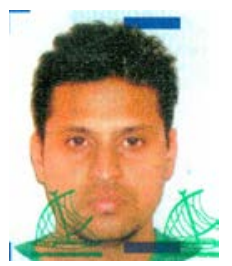

Ashneel Deo received the BTech degree from The University of the South Pacific (USP), Suva, Fiji, in 2014. Currently he is pursuing his BE degree from The University of the South Pacific (USP), Suva, Fiji. He also completed diploma in mechanical engineering from the Fiji National University, Fiji.

He joined The University of the South Pacific in 2014 as a technician in the Mechanical Engineering Department. Prior to USP, he worked as a mechanical engineer at Flour Mills of Fiji Limited in 2010. He has published more than 4 research papers in international conferences.

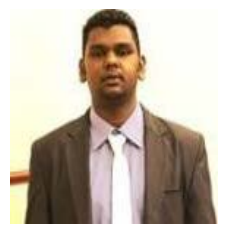

Jai Goundar received the BTech degree and the MSc degree from The University of the South Pacific (USP), Suva, Fiji, in 2009 and 2011, respectively. Currently he is pursuing his $\mathrm{PhD}$ degree in the area of marine current turbine.

He joined The University of the South Pacific in 2012 as an assistant lecturer. He has published more than 5 research papers in international journals and conferences. Mr. Jai Goundar is a student member of ASME.

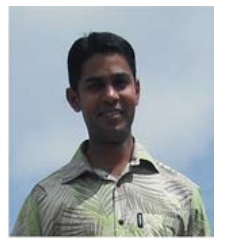

Sumesh Narayan received the BTech degree and the MSc degree from The University of the South Pacific (USP), Suva, Fiji, in 2003 and 2011, respectively. He received a gold medal for his MSc degree. Currently he is pursuing his $\mathrm{PhD}$ degree in the area of powder particulate materials processing.

He joined The University of the South Pacific in 2008 as an Assistant Lecturer. Prior to USP, he worked as a production supervisor at Fiji Sugar Cooperation in 2004 and project engineer at Shell oil Fiji and British Petroleum in 2005 to 2008. He has published more than 20 research papers in international journals and conferences.

Mr. Sumesh Narayan is a professional member of ASME.

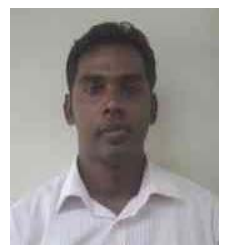

Niranjwan Chettier received the BTech degree from The University of the South Pacific (USP), Suva, Fiji, and his master of engineering from Anna University, India.

He joined The University of the South Pacific in 2012 as Manager Design and Engineering. Prior to USP, he worked at the Public Works Department. He has published more than 5 research papers in international journals and conferences. 